\title{
A REDAÇÃO DO ENEM ENTRE AS POLÍTICAS OFICIAIS E OFICIOSAS:O LUGAR DOS DIREITOS HUMANOS
}

\author{
The Enem essay between Official and Unofficial Policies: the place of \\ Human Rights
}

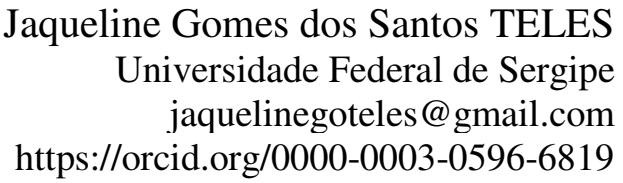

RESUMO: A cidadania, seguindo os princípios da Constituição Federal de 1988, figura como um dos principais objetivos da Educação Básica que deve ser garantido pela articulação de políticas públicas educacionais. Nessa perspectiva, o Exame Nacional do Ensino Médio (Enem), como política de avaliação, parece sinalizar uma tentativa de mensurar o alcance do objetivo final da educação ao exigir, entre as competências da prova de Redação, o respeito aos Direitos Humanos. No entanto, na contramão das políticas públicas oficiais que apresentam diretrizes e ferramentas para uma formação cidadã, as políticas oficiosas, fruto da organização de movimentos como o Escola Sem Partido, vêm ganhando espaço nas disputas políticas que são centrais para o cumprimento, ou não, da formação cidadã. $O$ objetivo deste artigo é sistematizar argumentos que sustentam as políticas oficiais e oficiosas no que diz respeito aos Direitos Humanos no âmbito da prova de redação do Enem. Para tanto, assumimos uma abordagem qualitativa que toma como base a pesquisa bibliográfica e a pesquisa documental. Os resultados mostram que as políticas oficiosas, a partir da organização e articulação de movimentos, interferem nas políticas oficiais e ameaçam a concepção de educação cidadã apregoada na Carta Magna.

PALAVRAS-CHAVE: Políticas Públicas; Redação do Enem; Direitos Humanos.

\begin{abstract}
Citizenship, following the principles of the 1988 Federal Constitution, appears as one of the main objectives of Basic Education, which must be guaranteed by the articulation of public educational policies. In this perspective, the National High School Examination (Enem), as an evaluation policy, seems to signal an attempt to measure the achievement of the ultimate goal of education by demanding, among the skills of the Essay exam, respect for Human Rights. However, contrary to official public policies that present guidelines and tools for citizen formation, unofficial policies, the result of the organization of movements such as Escola sem Partido, have been gaining space in political disputes that are central to compliance, or not, citizen
\end{abstract}


formation. The purpose of this article is to systematize arguments that support official and unofficial policies with regard to Human Rights within the scope of the Enem essay test. To do so, we take a qualitative approach based on bibliographic and documentary research. The results show that the unofficial policies, from the organization and articulation of movements, interfere in official policies and threaten the concept of citizen education proclaimed in the Constitution.

KEYWORDS: Public Policies; Enem Essay; Human Rights.

\section{CONSIDERAÇÕES INICIAIS}

Os Direitos Humanos têm seus pressupostos aliados ao conceito de cidadania; conforme Pinsky e Pinsky, em História da Cidadania, ser cidadão é, "em resumo, ter direitos civis" (2013, p. 9). A educação, nesse contexto, é condição para o conhecimento e o exercício desses direitos, "pré-requisito necessário da liberdade civil" nos dizeres de Marshall (1967), um dos principais teóricos que tratam da questão da cidadania:

A educação das crianças está diretamente relacionada com a cidadania, e, quando o Estado garante que todas as crianças serão educadas, este tem em mente, sem sombra de dúvida, as exigências e a natureza da cidadania. Está tentando estimular o desenvolvimento de cidadãos em formação. O direito à educação é um direito social de cidadania genuíno, porque o objetivo da educação durante a infância é moldar o adulto em perspectiva (MARSHALL, 1967, p.73).

Se considerarmos os percalços de uma sociedade cada vez mais globalizada e desigual, a Educação em Direitos Humanos (EDH) é indispensável para uma formação pautada na cidadania. Nesse contexto, a prova de Redação do Exame Nacional do Ensino Médio, o Enem, ao se alinhar com as Diretrizes Nacionais para a Educação em Direitos Humanos (DNEDH), se apresenta como uma política de avaliação que, de algum modo, deve contribuir para a consolidação da formação cidadã na educação brasileira já que interfere diretamente nas políticas públicas educacionais, modelando os currículos.

A cidadania deve ser objeto e objetivo da educação, como apregoa a Declaração Universal dos Direitos Humanos (ONU, 1948) e, por extensão, a Constituição Federal de 1988, chamada de Constituição Cidadã, que, em seu art. 205, indica o exercício pleno da cidadania como objetivo precípuo da educação e, em seguida, lista os princípios que devem ser observados no processo de ensino e aprendizagem (BRASIL, 1988, Art. 206): 
I - igualdade de condições para o acesso e permanência na escola;

II - liberdade de aprender, ensinar, pesquisar e divulgar o pensamento, a arte e o saber;

III - pluralismo de ideias e de concepções pedagógicas, e coexistência de instituições públicas e privadas de ensino;

IV - gratuidade do ensino público em estabelecimentos oficiais;

V - valorização dos profissionais da educação escolar, garantidos, na forma da lei, planos de carreira, com ingresso exclusivamente por concurso público de provas e títulos, aos das redes públicas;

VI - gestão democrática do ensino público, na forma da lei;

VII - garantia de padrão de qualidade;

VIII - piso salarial profissional nacional para os profissionais da educação escolar pública, nos termos de lei federal.

Como uma forma de replicar os princípios da Carta Magna, a legislação brasileira em vigor coloca a formação cidadã como um objetivo da educação, conforme consta na “Lei de Diretrizes e Bases da Educação" - LDB (Lei no 9.394/1996). Entretanto, não se sabe se (e como) esse objetivo está sendo cumprido ao término do seu ciclo, que se dá com o Ensino Médio. Por outro lado, o Ministério da Educação (MEC) parece tentar responder se o estudante se apropria dos discursos de cidadania, ao exigir o respeito aos Direitos Humanos (DH) na prova de Redação do Exame Nacional do Ensino Médio (Enem).

O Enem, segundo maior exame do mundo (DUARTE, 2019) ${ }^{1}$, surgiu em 1998 como uma política de avaliação vinculada ao Sistema Nacional de Avaliação da Educação Básica (Saeb), mas logo consolidou-se como uma política de seleção. Com a publicação da Portaria $n^{\circ}$ 109/2009, teve os seus objetivos ampliados (BRASIL, 2009):

I - oferecer uma referência para que cada cidadão possa proceder à sua auto avaliação com vistas às suas escolhas futuras, tanto em relação ao mundo do trabalho quanto em relação à continuidade de estudos; II estruturar uma avaliação ao final da educação básica que sirva como modalidade alternativa ou complementar aos processos de seleção nos diferentes setores do mundo do trabalho; III - estruturar uma avaliação ao final da educação básica que sirva como modalidade alternativa ou complementar aos exames de acesso aos cursos profissionalizantes, pósmédios e à Educação Superior; IV - possibilitar a participação e criar condições de acesso a programas governamentais; V - promover a certificação de jovens e adultos no nível de conclusão do ensino médio nos termos do artigo 38, §§ 1o - e 2o - da Lei no - 9.394/96 - Lei das

\footnotetext{
${ }^{1}$ O GaoKao, exame de admissão do Ensino Superior da República Popular da China, é o maior do mundo com 10 milhões de inscritos (2019), de acordo com o site da Folha de São Paulo.
} 
Diretrizes e Bases da Educação Nacional (LDB); VI - promover avaliação do desempenho acadêmico das escolas de ensino médio, de forma que cada unidade escolar receba o resultado global; VII promover avaliação do desempenho acadêmico dos estudantes ingressantes nas Instituições de Educação Superior.

Partindo do pressuposto que uma política pública é uma "diretriz elaborada com dois elementos fundamentais, a intencionalidade pública e o tratamento ou a resolução de um problema entendido como coletivamente relevante" (SECCHI, 2013, p. 2), as políticas podem assumir diferentes paradigmas em um dado contexto histórico. Diante disso, o exame dos discursos que ecoam das políticas, a partir dos documentos oficiais e oficiosos, pode ser fundamental no estudo das problemáticas que circundam a educação.

$\mathrm{Na}$ contramão das políticas públicas oficiais que apresentam diretrizes e ferramentas para a consolidação da formação cidadã na legislação educacional brasileira, observamos as ações de associações e movimentos conservadores (COSTA, 2018) ${ }^{2}$, como o "Escola sem Partido" (ESP), que se apresentam como políticas não oficiais - que aqui chamaremos de políticas oficiosas - e vêm ganhando espaço nas disputas políticas que são centrais para o cumprimento, ou não, da formação cidadã na Educação Básica.

A distinção entre oficial e oficioso é carente de uma literatura, sobretudo na pesquisa educacional, sendo mais recorrente em sites que tratam de dúvidas no âmbito da ortografia da Língua Portuguesa. No portal Ciberdúvidas da Língua Portuguesa ${ }^{3}$, temos que o principal sentido de documento oficial é aquele que é "declarado pela autoridade competente", já o oficioso é "particular, não oficial” (VIANA, 2007), cuja definição original é mencionada no blog Sobre Palavras ${ }^{4}$ (RODRIGUES, 2012):

A acepção original de oficioso - "prestativo, empenhado em ajudar" data do século XV e é hoje pouco usada, mas desdobrou-se numa outra que se legitima por curiosa oposição ao sentido de oficial: oficioso é aquilo que não é oficial, mas que se relaciona de alguma forma com o que é ou dele ganha chancela.

\footnotetext{
${ }^{2}$ Os resultados do estudo "Painel do Eleitor Brasileiro (2018)" - elaborado para o Instituto da Democracia e da Democratização da Comunicação - apontam para mudança no comportamento de parte do eleitorado brasileiro a partir da adesão a valores considerados conservadores.

${ }^{3}$ Criado em Portugal, o portal dispõe de um consultório constituído por um corpo de colaboradores que respondem a dúvidas do ponto de vista da ortografia, da fonética, da etimologia, da sintaxe, da semântica e da pragmática.

${ }^{4} \mathrm{O}$ blog tem como objeto o português falado no Brasil a partir do equilíbrio entre o tradicional e o novo.
} 
De forma congruente, nos manuais de Comunicação Social, no âmbito do telejornalismo, há uma categorização de fontes ${ }^{5}$ que, nos dizeres de Lage (2001), podem ser oficiais e, para isso, precisam partir do Estado, de empresas ou de organizações; e podem ser oficiosas que, mesmo partindo de uma instituição ou personalidade, não apresentam poder formal de representação.Considerando as políticas oficiosas que aqui investigamos, a partir das ações do Escola Sem Partido, as acepções parecem adequadas.

A escolha do ESP, como a política oficiosa a ser analisada, se justifica pelo fato de ser um dos principais movimentos que seguem na contramão dos documentos oficiais, sobretudo na perspectiva do respeito aos Direitos Humanos (DH), uma das competências exigidas na prova de redação do Enem, a política oficial que elegemos para esse trabalho. Desse modo, este artigo se alinha ao objetivo do dossiê da Revista X que traz como título "Políticas Linguísticas oficiais e oficiosas: da BNCC ao Escola sem Partido".

O Novo Enem, como ficou conhecido após a publicação da Portaria n ${ }^{\circ}$ 109/2009, manteve o comprometimento com a formação cidadã, conforme as edições anteriores, ao definir como objetivo precípuo a "avaliação do desempenho escolar e acadêmico dos participantes, para aferir o desenvolvimento das competências e habilidades fundamentais ao exercício da cidadania" (BRASIL, 2009). Todavia, dez anos depois, sem que a legislação educacional tenha alterado os seus princípios e objetivos, o termo cidadania deixa de aparecer vinculado ao objetivo do Enem, que se resume a "avaliação individual do desempenho do participante ao final do ensino médio" (BRASIL, 2019).

Diante disso, resta saber se (e como) as políticas oficiosas e oficiais mobilizam a questão dos Direitos Humanos (DH) no âmbito da redação do Enem, política educacional de avaliação. A partir de uma abordagem qualitativa, este artigo toma a pesquisa bibliográfica e a pesquisa documental para sistematizar argumentos que sustentam as políticas oficiais e oficiosas no que diz respeito aos DH no âmbito da redação do Enem. Entre os documentos oficiais destacamos a LDB, os PCN e DNEDH; entre os documentos oficiosos, tomamos o acervo do site do Escola Sem Partido, além dos projetos de leis em tramitação que, de alguma forma, refletem o posicionamento do ESP.

\footnotetext{
${ }^{5}$ Santos (2003, p. 76) em Jornalistas e Fontes de Informação: a sua relação na perspectiva da sociologia do jornalismo, define fontes como "atores que os jornalistas observam e entrevistam, no sentido do fornecimento de informação e sugestão noticiosa enquanto membros e representantes de grupos de interesses organizados, ou não, bem como de setores mais vastos da sociedade".
} 
Para tanto, o texto segue organizado em três seções que pretendem: i) sistematizar as principais orientações que aparecem nas políticas públicas oficiais para a consolidação da formação cidadã, tendo como ponto de partida as políticas de Educação em Direitos Humanos (EDH) e as diretrizes da prova de Redação do Enem; ii) destacar as tensões e os desdobramentos de parte das ações do MESP, no âmbito dos Direitos Humanos; iii) relacionar o Enem, como política de avaliação da Educação Básica, a partir da prova de redação, com as outras políticas oficiais e políticas oficiosas.

Este artigo é parte de uma pesquisa de doutoramento desenvolvida no Programa de Pós Graduação em Educação da Universidade Federal de Sergipe (PPGED/UFS) que relaciona a perspectiva cidadã da Redação do Enem com as políticas educacionais, no âmbito do projeto "Acesso, permanência e qualidade na Educação Básica e Educação Superior" do Grupo de Estudos Linguagem, Interação e Ensino - GELINS ${ }^{6}$.

Devido ao bom número de estudos sobre avaliações em larga escala, o GELINS publicou uma edição inteira de artigos relacionados ao Enem. Na obra, Freitag destaca a ausência de estudos, de fundamental importância, que avaliem o "impacto da prova do ENEM na modelagem dos currículos" (2015, p. 30). É a partir das provocações contidas na obra que gestamos a inquietação para tratar da competência V da Redação do Enem.

\section{A REDAÇÃ̃O DO ENEM E AS POLÍTICAS OFICIAIS NA CONSOLIDAÇÃO DA FORMAÇÃO CIDADÃ}

Considerando os Parâmetros Curriculares Nacionais de Língua Portuguesa (PCNLP), “o domínio da língua, oral e escrita, é fundamental para a participação social efetiva, pois é por meio dela que o homem se comunica, tem acesso à informação, expressa e defende pontos de vista, partilha ou constrói visões de mundo, produz conhecimento" (BRASIL, 1997, p. 15). Todavia, a redação escolar, como gênero textual, consolidou-se como treino: de texto narrativo, no ensino fundamental, como por exemplo, a tradicional tarefa "Minhas férias"; e de texto dissertativo, no ensino médio, para garantir um bom desempenho em exames de seleção para o ensino superior, tipo vestibulares.

Formado por dezenas de questões objetivas, os vestibulares só passaram a incluir a prova de Redação, como obrigatória, no final da década de 1970. O Decreto $\mathrm{n}^{\circ}$

${ }^{6}$ ANDRADE, 2016; FREITAG, 2014, 2015, 2016, 2017; TELES, 2017. 
79.298/1977 instituiu, no ensino médio, a disciplina “Técnicas de Redação" com o fito de minimizar o desempenho insatisfatório dos alunos em relação à produção textual escrita, mas tal medida não foi suficiente para solucionar a problemática. A década de 1980, além de romper com o pensamento tecnicista, colocou ensino de Língua Portuguesa no centro da discussão acerca da necessidade de melhorar a qualidade da educação, partindo de uma concepção de língua pautada no uso e na reflexão (BRASIL, 1997).

Antes de dar conta das políticas que surgem na década seguinte, vale destacar que a legislação brasileira inaugurou a temática educacional a partir da Constituição Federal de 1934 que estabelece a educação como direito de todos, dever da família e dos Poderes Públicos e traz, para a União, a responsabilidade de organizar a educação nacional a partir da elaboração de diretrizes. Para tanto, respalda o Conselho Nacional de Educação (CNE), que já existia, e coloca sob sua gerência o Plano Nacional da Educação (PNE).

A Constituição Federal de 1988, conhecida como Constituição Cidadã, institucionalizou os Direitos Humanos e colocou a dignidade da pessoa humana e o exercício da cidadania como elementos chave na formação (BRASIL, 1988). De forma congruente, a Lei de Diretrizes e Bases da Educação Nacional - LDB (Lei nº 9.394/1996), que surgiu para materializar a tarefa do CNE, em parceria com o MEC, de fixar as diretrizes e bases para a Educação Nacional e regular seus mecanismos coloca o exercício da cidadania como central no processo de ensino e aprendizagem (BRASIL, 1996).

No mesmo ano em que surgiu a LDB, o Brasil assinou o Programa Nacional de Direitos Humanos (PNDH) e, para atender a uma exigência da Organização das Nações Unidas (ONU), no âmbito da década das nações unidas para a Educação em Direitos Humanos (EDH), elaborou e publicou, em 2003, o Plano Nacional de Educação em Direitos Humanos (PNEDH). Assim, o MEC institucionalizou a EDH e assumiu o compromisso de apoiar ações para fortalecer atividades e estruturar materiais educativos.

Pode-se dizer que as políticas públicas para a educação em Direitos Humanos foram oficializadas, no Brasil, signatário da ONU, à medida que os pactos foram firmados. Pautado no plano de ação do Programa Mundial de Educação em Direitos Humanos, o PNEDH teve sua versão final publicada em 2006 que, após ampla divulgação e debate, consolidou-se como uma política pautada em um projeto de sociedade baseado na cidadania e na cultura de direitos humanos. Para o PNEDH (BRASIL, 2006 p. 23): 
A educação em direitos humanos deve estruturar-se nas diversidades, garantindo a cidadania, o acesso ao ensino, permanência e conclusão, a equidade (étnico-racial, religiosa, cultural, territorial, físico-individual, geracional, de gênero, de orientação sexual, de opção política, de nacionalidade, dentre outras) e a qualidade da educação.

Em 2010, o PNDH incluiu em sua reformulação um eixo que trata da EDH dando condições para, em 2012, o CNE estabelecer as Diretrizes Nacionais da Educação em Direitos Humanos (DNEDH) que - "tendo como princípios: a dignidade humana; a democracia na educação e no ensino; a valorização das diversidades; a transformação social; a interdisciplinaridade; e a sustentabilidade (BRASIL, 2012, p. 20)" - passam a orientar a prática e a funcionalidade da EDH inclusive na avaliação educacional:

Art. $6^{\circ}$ A Educação em Direitos Humanos, de modo transversal, deverá ser considerada na construção dos Projetos Políticos Pedagógicos (PPP); dos Regimentos Escolares, dos Planos de Desenvolvimento Institucionais (PDI); dos Programas Pedagógicos de Curso (PPC) das Instituições de Ensino Superior; dos materiais didáticos e pedagógicos; do modelo de ensino, pesquisa e extensão; de gestão; bem como dos diferentes processos de avaliação (BRASIL, 2012, p. 21).

É com base nas DNEDH (2012) que o edital de 2013 do Enem introduz a punição ao desrespeito aos Direitos Humanos como um dos critérios de anulação da prova de Redação do Enem. Mas, antes disso, o exame da legislação educacional em vigor mostra que os Direitos Humanos não apareciam como centrais para o sistema educacional. No entanto, a cidadania aparece como objeto e objetivo da educação brasileira nos moldes não só na CF de 1988 e da LDB, mas também das principais políticas curriculares.

Elaborado e aplicado pelo Instituto Nacional de Estudos e Pesquisas Educacionais Anísio Teixeira - Inep, o Enem surgiu para avaliar a educação básica no final da década de 1990, logo depois da publicação de políticas curriculares como os Parâmetros Curriculares Nacionais (PCN) e o Programa Nacional do Livro Didático (PNLD). Apesar de ter se tornado uma alternativa aos processos seletivos tradicionais, a Redação do Enem apresenta dissonância em relação às políticas curriculares "ao cobrar norma padrão e tipificar os erros em leves, médios e graves, sem, no entanto, apresentar justificativas ou embasamento linguístico - seja teórico, seja empírico" (FREITAG, 2014, p. 61).

Por outro lado, a perspectiva cidadã da legislação educacional em vigor 
fundamenta a competência extralinguística da Redação do Enem: o respeito aos Direitos Humanos. A prova se alinha às políticas de Educação em Direitos Humanos (EDH) ao incluir a necessidade de o aluno demonstrar "seu preparo para o exercício da cidadania, para atuar na realidade em consonância com os direitos humanos" (BRASIL, 2019a, p. 23) se configurando como um "novo paradigma de concepção do gênero escolar" que demanda um perfil de estudante ativo e engajado (ABREU, 2015, p. 97).

Na metodologia prevista pelo Inep, a prova de Redação do Enem é elaborada de forma a possibilitar que os participantes, a partir dos subsídios oferecidos, realizem uma reflexão escrita em uma tarefa identificada como situação-problema (BRASIL, 2019a, p. 5). O desempenho é avaliado por, pelo menos, dois professores, de forma independente, sem que um conheça a nota atribuída pelo outro. Para tanto, devem utilizar como critérios de correção as competências previstas na Cartilha do Participante (BRASIL, 2019a, p. 6):

I. Dominar linguagens - Demonstrar domínio da modalidade escrita formal da língua portuguesa; II. Compreender fenômenos - Compreender a proposta de redação e aplicar conceitos das várias áreas de conhecimento para desenvolver o tema, dentro dos limites estruturais do texto dissertativo-argumentativo em prosa; III. Enfrentar situaçõesproblema - Selecionar, relacionar, organizar e interpretar informações, fatos, opiniões e argumentos em defesa de um ponto de vista; IV. Construir argumentações - Demonstrar conhecimento dos mecanismos linguísticos necessários para a construção da argumentação; V. Elaborar propostas - Elaborar proposta de intervenção para o problema abordado, respeitando os direitos humanos.

Vale destacar que as provas de Redação do Enem nem sempre apresentaram esse mesmo quadro de competências. A instrução acerca do respeito aos Direitos Humanos (DH), por exemplo, aparece primeiro na edição do Enem de 2001, mas não ganha continuidade regular nas edições seguintes, como veio a acontecer das edições de 2005 em diante. É a partir do acompanhamento das políticas de DH que o Enem passa a cobrar com mais veemência uma formação cidadã dos estudantes por meio da prova de Redação.

Os efeitos retroativos, ou seja, a influência do exame na prática docente, se destacam, cada vez mais, nas produções científicas que trazem a prova de Redação do Enem como objeto de estudo, como podemos atestar em Silva (2017) e Vicentini (2015). Se concordarmos que o Enem, como política pública, modela o processo de ensino e 
aprendizagem que se estabelece nas escolas, temos na $\mathrm{V}$ competência da prova de Redação do Enem mais uma ferramenta para a consolidação da formação cidadã.

Na contramão desse avanço, o Escola Sem Partido, para citar um dos movimentos que discordam da exigência do respeito aos Direitos Humanos na prova de redação do Enem, propõe um projeto de educação centrado no conteúdo e sustentado em uma perspectiva de formação travestida de "neutra", como se discute no tópico a seguir.

\section{AS POLÍTICAS OFICIOSAS NO ÂMBITO DOS DIREITOS HUMANOS}

Conforme brevemente discutido na introdução, as políticas oficiosas que aqui nos interessam resultam das ações e das articulações do Escola sem Partido, e de outros movimentos correlatos, que têm servido de subsídio para as disputas que determinam os rumos das políticas públicas educacionais. Além disso, tais movimentos têm fomentado a elaboração de projetos de leis por parte de parlamentares ligados aos segmentos mais conservadores da sociedade que, na maioria das vezes, ferem os Direitos Humanos.

Para Hunt (2009), a mudança social e política, a partir dos Direitos Humanos, ocorre por meio de interações que resultam num processo de empatia. A autora, em sua obra "A invenção dos Direitos Humanos", observa que, no século XVIII, muitos dos leitores de romances aprenderam a estender o seu alcance de empatia (2009, p. 39):

Ao ler, eles sentiam empatia além de fronteiras sociais tradicionais entre os nobres e os plebeus, os senhores e os criados, os homens e as mulheres, talvez até entre os adultos e as crianças. Em consequência, passavam a ver os outros - indivíduos que não conheciam pessoalmente - como seus semelhantes, tendo os mesmos tipos de emoções internas.

Há de se dizer que a escola é um espaço de interação social propício para a formação da cidadania; aqui consideramos que a cidadania é também orientada pela concretização dos DH. Segundo o PNEDH, é na escola que se define a "ação institucional pedagógica e a prática e vivência dos direitos humanos” (BRASIL, 2006, p. 23):

a escola é local de estruturação de concepções de mundo e de consciência social, de circulação e de consolidação de valores, de promoção da diversidade cultural, da formação para a cidadania, de constituição de sujeitos sociais e de desenvolvimento de práticas pedagógicas. 
Com uma proposta adversa, o Escola sem Partido (ESP) surge em 2004 por iniciativa de Miguel Nagib, procurador do Estado de São Paulo. Com o lema "escola sem doutrinação", o ESP parte da premissa de que o professor tem se tornado uma ameaça por se aproveitar da audiência cativa de seus alunos para promover doutrinação política. Inspirado em um movimento norte-americano, o NoIndoctrination ${ }^{7}$, o ESP criou a página EscolasemPartido.org para reunir denúncias de pais e alunos preocupados com o grau de "contaminação político-ideológica" nas escolas e nas instituições de ensino superior:

Quando começávamos a pôr mãos à obra, tomamos conhecimento de que um grupo de pais e estudantes, nos EUA, movido por idêntica preocupação, já havia percorrido nosso caminho e atingido nossa meta: NoIndoctrination.org (NAGIB, 2019, s.p.).

O EscolasemPartido.org, mais que um portal de denúncias, é um típico espaço de polarização política seja pelo teor dos artigos: "Na Univesp, alunos são mantidos em isolamento ideológico contra o perigoso vírus do pluralismo" ou "Professora de português toma invertida após tentativa de promover ideologia de gênero"; seja pela definição do objeto de enfrentamento do movimento (ESCOLA SEM PARTIDO, 2020, s.p.):

No Brasil, quem promove a doutrinação político-ideológica em sala de aula, de forma sistemática e organizada, com apoio teórico (Gramsci, Althusser, Freire, Saviani, etc.), político (governos e partidos de esquerda, PT à frente), burocrático (MEC e secretarias de educação), editorial (indústria do livro didático) e sindical é a esquerda.

Há de se destacar que a disputa política em torno das políticas públicas educacionais é determinante para o estabelecimento, ou não, de uma formação cidadã. $O$ ESP relaciona o "problema" da doutrinação político-ideológica aos teóricos que embasaram uma concepção de educação emancipatória, provocando uma pauta para a formação docente; e, ao mesmo tempo, desqualifica o Plano Nacional do Livro Didático (PNLD) como a indústria do livro didático levantando uma discussão acerca do currículo.

\footnotetext{
${ }^{7}$ Como uma espécie de Fórum, o site americano < NoIndoctrination.org $>$, indisponível desde 2016, foi fundado por Luann Wright "ao perceber um viés crítico nos textos e nas atitudes de um certo professor de literatura de seu filho, que orientava a leitura de artigos qualificados por ela como "tendenciosos" sobre o racismo dos brancos contra os negros" (ESPINOZA; QUEIROZ, 2017, p. 50).
} 
Resta saber como, então, essa disputa alcança as políticas de avaliação, como o Enem.

O enfrentamento que o ESP propõe derruba o argumento de neutralidade defendido pelo movimento. Partindo do princípio de que os pais, por serem "donos de seus filhos" devem determinar o que deve ser ensinado, o ESP se pauta na regulamentação do Código do Consumidor e ignora a concepção de educação pública e gratuita. De acordo com Nagib, principal representante do ESP (NAGIB, 2013):

Tanto por força da Constituição, como por força do Código de Defesa do Consumidor e da Lei de Diretrizes e Bases da Educação Nacional, as escolas públicas e privadas têm o dever jurídico de educar e informar os estudantes sobre o direito que eles têm de não ser doutrinados por seus professores.

Ainda que o movimento Escola sem Partido coloque a chamada doutrinação na conta da esquerda e, ao mesmo tempo, contribua para uma educação cada vez mais desvinculada da formação cidadã, o respeito aos $\mathrm{DH}$ transcende a dicotomia direita e esquerda. Há de se dizer que os DH consistem em uma definição complexa que não escapa de contradições, sobretudo se considerarmos a perspectiva ocidental que tece os DH a partir de um viés social e liberal. Apesar desse paradoxo não ser objeto desse artigo, vale ressaltar que os DH não podem ser reduzidos a um movimento político, de esquerda.

Além de colocar a esquerda ${ }^{8}$ como alvo, o ESP, declara sua autonomia com relação a qualquer vinculação política, ideológica ou partidária, chegando a destacar que "não defende e não promove nenhum tópico da agenda liberal, conservadora ou tradicionalista. Logo, não é de direita" (ESCOLA SEM PARTIDO, 2020a, s.p.). Contrariando o argumento de autonomia ideológica, Moura (2016, p.23) mostra indícios de elo entre o coordenador Nagib e o principal think $\operatorname{tank}^{9}$ da direita brasileira, o Instituto Millenium ${ }^{10}$. De acordo com Frigotto, o ESP parte de um ultraconservadorismo econômico-social para

\footnotetext{
${ }^{8}$ Para Downs (1999), a diferença entre direita e esquerda repousa na intervenção do Estado, no âmbito da economia: o controle governamental interessa a "esquerda" e a liberdade de mercado satisfaz a "direita".

${ }^{9}$ Rigolin e Hayashi (2012), após um levantamento das principais definições acadêmicas para o termo, resumem os think tanks como "institutos de pesquisa, organizações privadas da sociedade civil, sem fins lucrativos que produzem informação e conhecimento com o objetivo central de influir em um ou mais aspectos do processo de formulação, implementação e/ou avaliação das políticas públicas” (2012, p. 25).

${ }^{10}$ Segundo o site oficial do instituto: "somos referência nas ideias modernas, nas redes sociais e no combate às fake news. Inovando sempre na comunicação sobre economia de mercado, democracia, debate de políticas públicas e liberdade individual. Junte-se aos grandes pensadores e influenciadores do Brasil!". Disponível em: <https://www.institutomillenium.org.br/institucional/quem-somos/> Acesso em: 10 abr. 2020.
} 
justificar um ensino neutro que atenda às demandas do mercado (2019, p. 4):

(...) os proponentes do movimento sabem muito bem que a maior parte dos professores sequer é filiada a partido político e, os que o são, pertencem a vários. $\mathrm{O}$ que eles pretendem é que o professor se constitua um tipo de robô ou máquina neutra e que ensine o que está programado e prescrito sob a orientação de institutos privados.

Segundo parecer ${ }^{11}$ publicado no site do ESP, o combate a "doutrinação e a propaganda ideológica, política e partidária nas escolas e universidades; e a usurpação pelas escolas e pelos professores - do direito dos pais dos alunos sobre a educação religiosa e moral dos seus filhos" (ESCOLA SEM PARTIDO, 2018, s.p.) é feito a partir de duas vertentes: o Programa Escola sem Partido (PESP) e a Associação Escola sem Partido (AESP). Para ampliar mecanismos que não permitam aos professores transferir aos alunos suas concepções morais e políticas, o PESP aposta em um projeto de lei que torna obrigatória a afixação em todas as salas de aula, do ensino fundamental ao médio, de um cartaz com os dizeres a seguir (PROGRAMA ESCOLA SEM PARTIDO, 2020):

\begin{abstract}
1 - O Professor não se aproveitará da audiência cativa dos alunos para promover os seus próprios interesses, opiniões, concepções ou preferências ideológicas, religiosas, morais, políticas e partidárias.

2 - O Professor não favorecerá nem prejudicará ou constrangerá os alunos em razão de suas conviç̧ões políticas, ideológicas, morais ou religiosas, ou da falta delas.

3 - O Professor não fará propaganda político-partidária em sala de aula nem incitará seus alunos a participar de manifestações, atos públicos e passeatas.

4 - Ao tratar de questões políticas, sócio-culturais e econômicas, o professor apresentará aos alunos, de forma justa - isto é, com a mesma profundidade e seriedade -, as principais versões, teorias, opiniões e perspectivas concorrentes a respeito da matéria.

5 - O Professor respeitará o direito dos pais dos alunos a que seus filhos recebam a educação religiosa e moral que esteja de acordo com suas próprias convicções.

6 - O Professor não permitirá que os direitos assegurados nos itens anteriores sejam violados pela ação de estudantes ou terceiros, dentro da sala de aula.
\end{abstract}

Ora, o ESP representa um braço conservador da sociedade e da política brasileira

\footnotetext{
${ }^{11}$ Redigido com o objetivo de contribuir para tramitação e aprovação dos anteprojetos de lei do Movimento Escola Sem Partido, cuja constitucionalidade tem sido questionada perante o Judiciário.
} 
que encontra na legislação educacional um campo fértil para a difusão de um pensamento da ultradireita, a retirada de direitos e, por meio de uma metodologia fascista, a institucionalização do controle e da perseguição dos professores, entre outras medidas.

O ESP fortalece a dicotomia entre direita e esquerda ao combater as questões de gênero com base no fundamentalismo religioso, nos valores da família e na definição dos professores como "defensores de partidos de esquerda e doutrinadores" (FRIGOTTO, 2019, p. 8). Contrariando esse entendimento, a Unesco publicou, em 2004, uma pesquisa que revelou que a maioria dos professores assumem uma perspectiva homofóbica. A pesquisa, intitulada "Perfil dos Professores Brasileiros", foi realizada no ano de $2002 \mathrm{em}$ todos os estados brasileiros com 5 mil professores, tanto da rede pública como da privada. Desses, 59,7\% afirmaram ser inadmissível que uma pessoa tenha relações homossexuais e 21,2\% não gostariam de ter vizinhos homossexuais (UNESCO, 2004, p.144). Pesquisa semelhante mostrou que a homofobia alcança pais e alunos (ABRAMOVAY et al., 2004).

Diante desse cenário, o governo federal lançou, em 2004, o programa Brasil sem Homofobia - Programa de Combate à Violência e à Discriminação contra LGBT e Promoção da Cidadania Homossexual e, por meio do projeto Escola sem Homofobia, publicou, em 2011, um material de apoio para os educadores com referências teóricas e sugestões de atividades para trabalhar o tema da diversidade sexual. O material, chamado de forma pejorativa de "Kit Gay" por parlamentares ligados às bancadas religiosas, não chegou a ser distribuído nas escolas e o projeto foi suspenso. Esse episódio de "pânico moral" fortaleceu o conservadorismo em torno da "ideologia de gênero" (LEITE, 2019).

Uma década após a criação do ESP, a onda conservadora voltou a ser destaque na dinâmica da aprovação do PNE. Entre as principais polêmicas que renderam a morosidade da aprovação, destacou-se o debate da igualdade de gênero, umas das metas do PNE derrubada na Câmara dos Deputados. No texto original constava que a educação deveria promover a superação da "desigualdade racial, regional, de gênero e de orientação sexual". Por pressão da maioria dos parlamentares, o texto foi substituído por: "promoção da cidadania e erradicação de todas as formas de discriminação" (KLEIN, 2015, p. 150).

É nesse contexto de disputa das políticas educacionais que surgem os primeiros projetos de lei do ESP no Rio de Janeiro, em 2014. Resultado de uma parceria com o coordenador Nagib, o então deputado estadual Flávio Bolsonaro (PP-RJ) apresentou o 
Projeto de Lei no 2974/2014 no âmbito estadual intitulado "Programa Escola Sem Partido" (RIO DE JANEIRO, 2014). De forma congruente, o vereador Carlos Bolsonaro (PP-RJ) apresentou o Projeto de Lei $\mathrm{n}^{\circ} 876 / 2014$, com o mesmo teor, voltado para as escolas municipais (RIO DE JANEIRO, 2014). Desde então, o portal do PESP tem disponibilizado dois modelos, a versão municipal e a versão estadual do anteprojeto.

$\mathrm{Na}$ mesma linha, o deputado federal Erivelton Santana (PSC-BA) apresentou o Projeto de Lei no 7.180/2014, que ficou conhecido como "Projeto Escola Sem Partido", com o objetivo de incluir na LDB: "o respeito às convicções do aluno, de seus pais ou responsáveis, dando precedência aos valores de ordem familiar sobre a educação escolar nos aspectos relacionados à educação moral, sexual e religiosa" (BRASIL, 2014). No ano seguinte, 2015, o deputado federal Rogério Marinho (PSDB-RN) criou o Projeto de Lei $\mathrm{n}^{\circ}$ 1.411/2015 para tipificar o crime de "assédio ideológico" - com previsão de aumento de pena, caso o agente seja educador - que é definido como (BRASIL, 2015):

toda prática que condicione $\mathrm{o}$ aluno a adotar determinado posicionamento político, partidário, ideológico ou qualquer tipo de constrangimento causado por outrem ao aluno por adotar posicionamento diverso do seu, independente de quem seja o agente.

De forma complementar, o deputado federal Eros Biondini (PROS-MG) apresentou o Projeto de Lei n ${ }^{\circ}$ 2.731/2015 para garantir que fosse "proibida a utilização de qualquer tipo de ideologia na educação nacional, em especial o uso da ideologia de gênero, orientação sexual, identidade de gênero e seus derivados, sob qualquer pretexto" (BRASIL, 2015a) e o deputado federal Izalci Ferreira (PSDB-DF) ${ }^{12}$ propôs a inclusão do Programa Escola sem Partido na LDB, por meio do Projeto de Lei $n^{\circ} 867$ de 2015 sugerindo um novo rol de princípios para o sistema educacional (BRASIL, 2015b):

I - neutralidade política, ideológica e religiosa do Estado; II - pluralismo de ideias no ambiente acadêmico; III - liberdade de aprender, como projeção específica, no campo da educação, da liberdade de consciência; IV - liberdade de crença; V - reconhecimento da vulnerabilidade do educando como parte mais fraca na relação de aprendizado; VI educação e informação do estudante quanto aos direitos compreendidos em sua liberdade de consciência e de crença; VII - direito dos pais a que

\footnotetext{
${ }^{12}$ Parlamentar que ficou conhecido pelo projeto de lei que objetivava a retirada da obrigatoriedade do ensino das disciplinas de Sociologia e Filosofia no Ensino Médio.
} 
seus filhos recebam a educação moral que esteja de acordo com suas próprias convicções.

Para consolidar as suas proposituras, também em 2015, o deputado Izalci Ferreira (PSDB-DF) mobilizou uma audiência, realizada pela Comissão de Educação da Câmara dos Deputados, com o seguinte tema: Doutrinação Política e Ideológica nas Escolas. É dessa maneira que as políticas oficiosas, que aqui examinamos com base nas ações do ESP, vão dando nova conotação para as políticas educacionais e promovem o abrandamento da perspectiva cidadã da formação, objetivo nuclear da Educação Básica.

\section{A REDAÇÃO DO ENEM ENTRE AS POLÍTICAS OFICIAIS E OFICIOSAS}

A pretendida formação cidadã tem centralidade nas disputas políticas e tende a ser mais tensionada nas políticas públicas educacionais que têm os jovens como principais atores, como é o caso do Exame Nacional do Ensino Médio (Enem).

Em meio ao crescimento do Escola sem Partido, aliado ao apoio de parlamentares ligados a segmentos religiosos mais conservadores, a edição do Enem de 2015 foi alvo de polêmica. $\mathrm{O}$ tema proposto para a redação A persistência da violência contra a mulher na sociedade brasileira e o destaque para a frase de Simone de Beauvoir "Não se nasce mulher, torna-se mulher", em uma das questões do eixo de Ciências Humanas, resultou em ataques amplamente divulgados na mídia que questionavam a neutralidade ideológica da prova, sobretudo nas redes sociais com a utilização da hashtag ${ }^{13}$ \#enemfeminista.

Embora a exigência do respeito aos Direitos Humanos (DH) - inclusive que a sua inobservância seria utilizada como critério de anulação da prova - sempre estivesse na Cartilha de Redação do Enem, o ESP só passou a questioná-la quando a proposta da redação tratou da violência contra a mulher, em 2015. De acordo com o coordenador do ESP, com essa exigência "os participantes se veem forçados a abjurar de suas crenças e convicções para não perder a chance de ingressar numa universidade" (NAGIB, 2018).

Assim, após a realização da edição do Enem 2015, a associação do ESP, oficialmente registrada ${ }^{14}$, ingressou com uma ação civil pública com o objetivo de impedir

\footnotetext{
${ }^{13}$ Hashtag é uma expressão comum entre os usuários das redes sociais para definir uma palavra-chave antecedida por um símbolo (\#) conhecido como jogo da velha.

${ }^{14}$ Além da Associação Escola sem Partido, Nagib abre, em meados de 2015, a empresa Escola sem Partido
} 
que o Inep anulasse qualquer redação por desrespeito aos DH. O pedido foi negado pois a associação não poderia promover a ação civil pública por ter sido constituída há menos de um ano. Diante disso, a associação mudou a estratégia e enviou representações às unidades do Ministério Público Federal (MPF) de cada estado brasileiro. Dessa maneira, coube ao MPF de Goiás recomendar que o Inep publicasse, no prazo de 15 dias, e em seu portal eletrônico, as bases filosóficas, epistemológicas e normativas que consubstanciam os DH na elaboração e na correção da prova de redação.

O Inep, ao responder à recomendação, considerou que as bases filosóficas e epistemológicas que norteiam o exame estão fundamentadas na legislação educacional em vigor, a partir dos princípios da educação previstos na LDB, concatenados com a Constituição Federal de 1988; no Plano Nacional de Educação em Direitos Humanos (PNEDH); e nas Diretrizes Nacionais para a Educação em Direitos Humanos (DNEDH).

Ainda assim, em 2016, Nagib, coordenador da associação ESP, requereu à Procuradoria da República no Distrito Federal a responsabilização do presidente do Inep por crime de abuso de autoridade alegando atentado contra a liberdade de consciência e de crença dos candidatos e ato de improbidade administrativa pela violação do princípio da impessoalidade. Com o argumento de se tratar apenas de uma discordância quanto a critério de avaliação do exame, a representação foi liminarmente arquivada. Um ano depois da constituição formal da associação, nova ação pública foi ajuizada para invalidar a regra do Enem de respeito aos Direitos Humanos (DH), mas, sob a alegação de que a regra visava proteger aos DH e a prevenir o discurso de ódio, a solicitação foi indeferida.

Em meados de 2017, relatores do Alto Comissariado de Direitos Humanos (DH) da $\mathrm{ONU}^{15}$, enviaram um documento ao governo brasileiro solicitando apresentação de razões que justificassem a aplicação de leis propostas pelo ESP. No documento ${ }^{16}$, a ONU afirma que o fomento da violação ao direito de expressão nas escolas representa uma "censura significativa" (CDHPF, 2017). Em resposta, o governo alegou que os projetos de lei

Treinamento e Aperfeiçoamento Eireli - ME voltada para o ramo do treinamento em desenvolvimento profissional e gerencial, com patrimônio de aproximadamente 80 mil reais, disponível em: $<$ https://www.empresascnpj.com/s/empresa/escola-sem-partido-treinamento-e-aperfeicoamento-eireli-nomefantasia-escola-sem-partido/22743156000103 > Acesso em: 28 abr. 2020.

$\frac{15}{15}$ Koumbou Boly Barry, relatora especial para o direito humano à educação; David Kaye, relator especial para promoção e proteção do direito à liberdade de opinião e expressão; e Ahmed Shaheed, relatora especial para liberdade de religião e de crença.

16 Disponível em: <https://campanha.org.br/wp-content/uploads/2017/04/OLBrazileducation-PortuguesFINAL..pdf>. Acesso em: 02 mai. 2020. 
seguiram "as regras e o espírito de democracia e no lugar institucional adequado, ou seja, o Congresso Nacional” (CDHPF, 2017) ${ }^{17}$. A ONU também criticou a influência de ideias conservadoras na Base Nacional Comum Curricular (BNCC) que, assim como o Plano Nacional da Educação (PNE), só foi aprovada depois que termos como "gênero" e "orientação sexual" foram retirados ou substituídos na redação original.

Nesse contexto, a associação ESP reiterou seu pedido para que fosse invalidada a regra que anula a prova de Redação do Enem no caso de desrespeito aos DH que, após indeferimento e recurso, foi finalmente deferido pela $5^{\text {a }}$ Turma do Tribunal Regional Federal da $1^{\text {a }}$ Região (TRF-1), por maioria de votos. A Advocacia Geral da União (AGU) e a Procuradoria Geral da República (PGR) recorreram, mas a Ministra Cármen Lúcia, então presidente do STF, garantiu, na véspera da edição do Enem 2017, a decisão do TRF1. Em entrevista ao portal de notícias $O$ Globo, a ministra declarou (BRESCIANI, 2017):

Não se desrespeitam direitos humanos pela decisão que permite ao examinador a correção das provas e a objetivação dos critérios para qualquer nota conferida à prova. $\mathrm{O}$ que os desrespeitaria seria a mordaça prévia do opinar e do expressar do estudante candidato

Com essa medida a ministra garante um retrocesso para a Educação em Direitos Humanos (EDH), que chega a principal política de avaliação da educação básica para, de algum modo, servir de parâmetro para atestar, ou não, o alcance da formação cidadã. Além disso, coloca o exame como um instrumento de violação da liberdade de expressão, “mordaça prévia”, sem o sensível pesar acerca do caráter fascista das ações e do percurso do ESP que confere, aos seus projetos de lei, o adequado apelido de "leis da mordaça".

$\mathrm{Na}$ ocasião da decisão da ministra, o vereador Carlos Bolsonaro (PSC-RJ), publicou no seu perfil do Twitter ${ }^{18}$ uma foto do seu pai, Jair Bolsonaro, exibindo uma camisa com a frase "Direitos humanos: esterco da vagabundagem". Há de se destacar que referido vereador sugere, na legenda da sua publicação, que a frase seja tema da redação do Enem caso seu pai seja eleito presidente (CONGRESSO EM FOCO, 2017).

A frase reflete um posicionamento político-ideológico recorrente nas campanhas

17 Disponível em: <https://static.poder360.com.br/2017/06/itamaraty-onu-escola-sem-partido12jun2017.pdf>. Acesso em: 02 mai. 2020.

${ }^{18}$ Twitter é uma rede social que permite aos usuários enviar e receber atualizações pessoais. 
da família Bolsonaro ao mesmo tempo em que apresenta, de forma pejorativa e chula, uma concepção reducionista dos Direitos Humanos, como ferramenta do Direito Penal. Em 2019, após a eleição de Bolsonaro, as discussões acerca do viés político da prova do Enem ganharam mais espaço. Entre as suas primeiras declarações sobre a prova do Enem, o presidente deixou clara a sua prioridade (EXAME, 2019):

\begin{abstract}
Queremos colocar nessas provas do Enem matérias onde a grande maioria reconheça a família. Reconheça o valor do Estado brasileiro. Respeite as crianças na sala de aula. Sem ideologia política ou de gênero. Queremos que a garotada estude, sim. Sabendo que o que lhes será cobrado neste será aquilo que os pais querem. E aquilo que interessa ao Brasil (EXAME, 2019, s.p.).
\end{abstract}

O discurso da neutralidade, que, como se sabe, é uma falácia, ao aparecer na liderança do país, já sinaliza os caminhos das políticas educacionais. Na mesma linha, o presidente do Inep, ressaltou que “(os estudantes) não vão fazer uma prova de Direitos Humanos (DH), mas uma que percorre os conteúdos escolares que devem ser cobrados. Se a questão envolve DH, entrará desde que bem formulada e não tire o foco do conteúdo" (BARONE, 2019). No entanto, em 2019, Nagib anunciou em suas redes sociais a suspensão das atividades do ESP por considerar que tem "poucas chances de avançar sem o apoio político do presidente Jair Bolsonaro" (SANTIAGO, 2019, s.p.).

Apesar do anúncio, centenas de projetos de lei, nos moldes do anteprojeto elaborado pelo "Escola sem Partido" (ESP), seguem em tramitação em câmaras municipais, assembleias legislativas e no Congresso Nacional. O fato de as ações do ESP não sofrerem a pausa anunciada pelo seu fundador pode estar relacionada com uma estratégia de engajamento, comum nas redes sociais. A postagem que anunciava o fim do movimento foi carregada não só de solicitações de permanência do movimento ESP, muitos seguidores enalteceram as contribuições do ESP para uma educação "neutra".

Ademais, de acordo com a maioria dos sites de notícias, a edição do Enem 2019 chamou atenção pela "neutralidade ideológica" na prova objetiva e na redação, cujo tema foi a Democratização do acesso ao cinema no Brasil. Vale destacar, que a "neutralidade é impossível porque não existe conhecimento desinteressado" (SAVIANI, 2011, p. 8).

Como o ESP, repercutem movimentos em defesa da neutralidade ideológica na escola como o "Escola Livre" que conseguiu a aprovação de um projeto de lei, em âmbito 
estadual, que logo depois foi caracterizado como inconstitucional pelo STF (PONTES, 2017). De forma similar, um julgamento virtual do Supremo Tribunal Federal (STF), em2020, decidiu pela inconstitucionalidade da Lei $n^{\circ}$ 1.516/2015 (Novo Gama - GO, 2015) que proibia a utilização de material didático com conteúdo relativo à diversidade de gênero (VALOR ECONÔMICO, 2020). As respostas demoram a chegar e, enquanto não chegam, os professores seguem vítimas de uma política de perseguição que fere os $\mathrm{DH}$.

Nesse contexto de disputa, a Educação em Direitos Humanos (EDH) segue ainda mais necessária. Se por um lado, movimentos como o Escola sem Partido - com o apoio institucional de órgãos estratégicos como o STF, na pessoa da ministra Carmem Lúcia defendem a liberdade de expressão para garantir que o respeito aos Direitos Humanos deixem de ser uma regra; por outro lado, pesquisadores e professores que estão na ponta das políticas educacionais - seja no contexto escolar, na pesquisa ou na extensão - seguem denunciando as ações desses movimentos que, na verdade, violam os Direitos Humanos sistematicamente, sobretudo no controle das políticas educacionais e do trabalho docente.

A distinção das percepções acima revela intencionalidades políticas muito bem consolidadas que estão a serviço de um projeto de educação que requer sujeitos adestrados para atender as necessidades políticas e econômicas de um sistema neoliberal em detrimento de uma educação emancipatória que busca a transformação da sociedade.

Seguem cada vez mais necessários estudos sobre os desdobramentos e as tensões entre as políticas públicas educacionais - formação docente, currículo e avaliação. Os resultados desses estudos podem subsidiar novas políticas, evitar retrocessos e propor avanços no campo das políticas públicas que devem, como preconiza a legislação educacional em vigor, servir de suporte e instrumento para o exercício da cidadania.

\section{CONSIDERAÇÕES FINAIS}

O ensino de Língua Portuguesa, aqui incluída a Redação, é um instrumento de cidadania por excelência já que, por meio da garantia da competência linguística, pode fazer com que o aluno tenha vez e voz para refletir e transformar a sua realidade. Nessa perspectiva, segue a legislação educacional em vigor, em consonância com a Constituição Federal de 1988. Com esse cenário, a Educação em Direitos Humanos (EDH) surge com respaldo e alcança, a maior política de avaliação da Educação Básica, o Enem. 
Atendendo às Diretrizes Nacionais para a Educação em Direitos Humanos (DNEDH), o Enem exige, além das competências linguísticas da prova de Redação, o respeito aos Direitos Humanos (DH). Desse modo, o exame parece tentar mensurar o alcance do objetivo final da educação, a formação cidadã, prevista na Carta Magna.

$\mathrm{O}$ trabalho aqui apresentado, com o objetivo de sistematizar argumentos que sustentam as políticas oficiais e oficiosas no tocante aos direitos humanos no âmbito da prova de redação do Enem. A sistematização que aqui apresentamos deixou evidente o processo de enfraquecimento das políticas oficiais em detrimento do avanço das políticas oficiosas, resultado das ações de movimentos que, sob o falso argumento da neutralidade ideológica, defendem um projeto político para a educação pautado no silenciamento do professor, a partir de perseguições e denúncias, e na alienação do aluno. Dessa maneira, na contramão das políticas oficiais, as políticas oficiosas colocam a educação em disputa.

Os resultados mostram que as políticas oficiosas, a partir da organização e articulação de movimentos, interferem nas políticas oficiais e ameaçam a concepção de educação cidadã apregoada na Carta Magna seja por meio da mobilização de projetos de lei nas esferas municipal, estadual e federal, seja pela censura da prática docente. Dessa maneira, as políticas oficiosas, ignoram duas questões fundamentais que devem ser problematizados em produções científicas: i) a concepção de educação apregoada na Carta Magna é centrada na cidadania e no respeito aos Direitos Humanos; ii) a competência de legislar sobre as bases da educação é privativa da União.

Diante do que foi discutido, as políticas públicas devem ser, cada vez mais, protagonistas de estudos para que seja possível entender e intervir nas problemáticas da educação. Nesse sentido, as pesquisas educacionais que se interessam pelas políticas oficiais devem incluir os discursos das políticas oficiosas, pois a percepção dos bastidores das políticas pode ser determinante não só para a compreensão dos fenômenos educacionais, mas para a intervenção no cenário de disputa político que está posto.

\section{REFERÊNCIAS}

ABRAMOVAY, M.; CASTRO, M.; SILVA, L. Juventudes e sexualidade. Brasília: Unesco, 2004. 
ABREU, R. Exercício da cidadania e direitos humanos: as funções da competência V na redação do Enem. In: SILVA. L; FREITAG, R. (Org.). Linguagem, interação e sociedade: diálogos sobre o Enem. João Pessoa: Editora do CCTA, p. 97-108, 2015.

ANDRADE, S. A norma linguística na prova de Linguagens, Código e suas Tecnologias e na redação do ENEM. In: Anais do III SEDiAr, p. 4331-4343, 2016.

BARONE, I. O que esperar do primeiro Enem de Bolsonaro? Gazeta do Povo, 02 de novembro de 2019. Disponível em: <https://www.gazetadopovo.com.br/educacao/o-queesperar-do-enem-2019-primeiro-de-bolsonaro/> Acesso em: 12 mar. 2020.

BRESCIANI, E. Carmem Lucia mantém liminar, e regra sobre direitos humanos não zera redação no Enem. O Globo, 04 de novembro de 2017. Disponível em: $<$ https://oglobo.globo.com/sociedade/educacao/enem-e-vestibular/carmen-lucia-mantemliminar-regra-sobre-direitos-humanos-nao-zera-redacao-no-enem-22029758>. Acesso em: 12 abr. 2020.

BRASIL. Decreto $n^{\circ} 79.298 / 1977$. Altera o Decreto $n^{\circ} 68.908$, de 13 de julho de 1971, e dá outras providências. Brasília, 24 de fevereiro de 1977.

BRASIL. Constituição da República Federativa do Brasil. Brasília: Senado Federal, 1988.

BRASIL. Lei $n^{\circ}$ 9.394/1996: Estabelece as Diretrizes e Bases da Educação Nacional. Brasília, 23 de dezembro de 1996.

BRASIL. Ministério da Educação. Parâmetros Curriculares Nacionais. Introdução aos Parâmetros Curriculares Educacionais. Brasília, 1997.

BRASIL. Ministério da Educação. Instituto Nacional de Estudos e Pesquisas Educacionais Anísio Teixeira - INEP. Portaria MEC $n^{\circ} 438$, de 28 de maio de 1998. Institui o Exame Nacional do Ensino Médio - ENEM. Disponível em: $<$ http://www.editoramagister.com/doc_348638_Portaria_n\%C2\%BA_438_de_28_de_maio _de_1998.aspx>. Acesso em: 02 abr. 2020.

BRASIL. Comitê Nacional de Educação em Direitos Humanos. Plano Nacional de Educação em Direitos Humanos. Brasília: Secretaria Especial dos Direitos Humanos, Ministério da Educação, Ministério da Justiça, UNESCO, 2006.

BRASIL. Ministério da Educação. Instituto Nacional de Estudos e Pesquisas Educacionais Anísio Teixeira - INEP. Portaria MEC $n^{\circ}$ 109, de 27 de maio de 2009. Estabelece a sistemática para a realização do Exame Nacional do Ensino Médio no exercício de 2009. Disponível em: <encurtador.com.br/EPS13> Acesso em: 02 abr. 2020.

BRASIL. Ministério da Educação. Conselho Nacional de Educação. Resolução $n^{o} 1$ de 30 de maio de 2012. Estabelece Diretrizes Nacionais para a Educação em Direitos Humanos. Brasília, 2012. 
BRASIL. CÂMARA DOS DEPUTADOS. Projeto de Lei 7180/2014. Altera o art. $3^{\circ}$ da Lei $n^{\circ}$ 9.394, de 20 de dezembro de 1996, que estabelece as diretrizes e bases da educação nacional. Brasília: 24 de fevereiro de 2014. Disponível em: $<$ https://www.camara.leg.br/proposicoesWeb/fichadetramitacao?idProposicao=606722> Acesso em: 18 abr. 2020.

BRASIL. CÂMARA DOS DEPUTADOS. Projeto de Lei 1.411/2015. Tipifica o crime de Assédio Ideológico e dá outras providências. Brasília: 06 de maio de 2015. Disponível em: $<$ https://www.camara.leg.br/proposicoesWeb/fichadetramitacao?idProposicao=1229808> Acesso em: 18 abr. 2020.

BRASIL. CÂMARA DOS DEPUTADOS. Projeto de Lei 2731/2015. Altera a Lei $n^{o}$ 13.005, de 25 de junho de 2014, que estabelece o Plano Nacional de Educação - PNE e dá outras providências. Brasília: 20 de agosto de 2015a. Disponível em: $<$ https://www.camara.leg.br/proposicoesWeb/fichadetramitacao?idProposicao=1672692 >A cesso em: 18 abr. 2020.

BRASIL. CÂMARA DOS DEPUTADOS. Projeto de Lei 867/2015. Inclui, entre as diretrizes e bases da educação nacional, o "Programa Escola sem Partido" - Apensado ao PL 7180/2014. Brasília: 23 de março de 2015b. Disponível em: $<$ https://www.camara.leg.br/proposicoesWeb/fichadetramitacao?idProposicao=1050668 $>$ A cesso em: 18 abr. 2020.

BRASIL. Ministério da Educação. Base Nacional Curricular Comum. Brasília: 2018.

BRASIL. Ministério da Educação. Instituto Nacional de Estudos e Pesquisas Educacionais Anísio Teixeira - Inep. Edital $n^{\circ} 14$, de 21 de março de 2019. Exame Nacional do Ensino Médio - $\quad$ Enem 2019. Disponível em: $<$ http://download.inep.gov.br/educacao_basica/enem/edital/2019/edital_enem_2019.pdf $>$. Acesso em: 04 abr. 2020.

BRASIL. Ministério da Educação. Instituto de Pesquisas Educacionais Anísio Teixeira. (Inep). A redação no Enem 2019: cartilha do participante. Brasília, 2019a.

DUARTE, L. China quer ampliar acesso ao Gaokao, o Enem do País. Folha de São Paulo, São Paulo, 05 de junho de 2019. Disponível em: $<$ https://www1.folha.uol.com.br/colunas/luiza-duarte/2019/06/china-quer-ampliar-acessoao-gaokao-o-enem-do-pais.shtml>. Acesso em: 22 abr. 2020.

CDHPF. Movimento Educação Democrática: contraponto ao crescente conservadorismo educacional. Passo Fundo, 30 de junho de 2017. Disponível em: <https://cdhpf.org.br/artigos/3489/> Acesso em: 09 abr. 2020.

CONGRESSO EM FOCO. Em meio à polêmica do Enem, Bolsonaro chama direitos humanos de "esterco da vagabundagem". 05 de novembro de 2017. Disponível em: <encurtador.com.br/dklJK> Acesso em: 09 mar. 2020. 
COSTA, G. Estudo indica reposicionamento do voto do eleitor conservador. Agência Brasil. Brasília, 29 de outubro de 2018. Disponível em: $<$ https://agenciabrasil.ebc.com.br/politica/noticia/2018-10/estudo-indicareposicionamento-do-voto-do-eleitor-conservador>. Acesso em: 22 abr. 2020.

DOWNS, A. Uma teoria econômica da democracia. Editora USP. São Paulo: 1999.

ESCOLA SEM PARTIDO. Parecer sobre a constitucionalidade do programa escola sem partido. Brasília, 18 de junho de 2018. Disponível em: <http://escolasempartido.org/wpcontent/uploads/2018/02/pfesp.pdf>Acesso em: 12 mar. 2020.

ESCOLA SEM PARTIDO. Não existe doutrinação de direita? (matéria sem data e autoria). 2020. Disponível em: <http://www.escolasempartido.org/perguntas-e-respostas/> Acesso em: 12 mar. 2020.

ESCOLA SEM PARTIDO. O ESP é de direita? (matéria sem data e autoria). Disponível $\mathrm{em}:<$ http://www.escolasempartido.org/perguntas-e-respostas/> 2020a. Acesso em: $12 \mathrm{mar}$. 2020 .

ESPINOZA, B.; QUEIROZ, F. Breve Análise Sobre as Redes do Escola Sem Partido. In: FRIGOTTO, G. (Org.). Escola "Sem" Partido: esfinge que ameaça a educação e a sociedade brasileira. Rio de Janeiro: UERJ, LPP, 2017.

EXAME. Bolsonaro quer que prova do Enem reconheça a "família" e "Estado Brasileiro".08 de junho de 2019. Disponível em: <https://exame.com/brasil/bolsonaroquer-prova-do-enem-que-reconheca-familia-e-estado-brasileiro/>. Acesso em: 04 mai. 2020 .

FREITAG, R. Prova de redação do Enem: divergências entre as orientações para a prática e as diretrizes de avaliação. Interdisciplinar. Ano IX, v.20, jan./jun. Itabaiana SE, p.61-72, 2014.

FREITAG, R.; CUNHA, F.; SANTANA, J. O desempenho na prova do Enem da rede estadual de Sergipe. In: SILVA, L; FREITAG R. (Orgs.) Linguagem, interação $e$ sociedade: diálogos sobre o Enem. João Pessoa: CCTA, p.163-171, 2015.

FREITAG, R. A nota do ENEM: acesso e permanência na Universidade. (Re)pensando as licenciaturas, p.75-90, 2016.

FREITAG, R. et al. Enem: motivações e expectativas de estudantes da rede pública estadual de Sergipe. Scientia Plena, São Cristóvão SE, v. 13, n. 5, p. 1-10, 2017.

FRIGOTTO, G. Prefácio. In: BATISTA, E.; ORSO, P.; LUCENA, C. (Orgs.). Escola sem partido ou a escola da mordaça e do partido único a serviço do capital. Uberlândia: Navegando Publicações, 2019. 
HUNT, L. A invenção dos direitos humanos: uma história. São Paulo: Companhia das Letras, 2009.

KLEIN, R. Questões de gênero e sexualidade nos planos educacionais. Coisas do Gênero. São Leopoldo. v.1, n. 2, p. 145-156, ago./dez., 2015.

LAGE, N. Relacionamento do repórter com as fontes: procedimentos e teoria. Associação Nacional dos Programas de Pós-Graduação em Comunicação. Brasília: 2001.

LEITE, V. A captura das crianças e dos adolescentes: refletindo sobre controvérsias públicas envolvendo gênero e sexualidade nas políticas de educação. Série-Estudos, Campo Grande, MS, v. 24, n. 52, p. 11-30, set./dez., 2019.

MARSHALL, T. Cidadania, Classe Social e Status. Rio de Janeiro: Zahar, 1967.

MOURA, F. "Escola Sem Partido": relações entre estado, educação e religião e os impactos no ensino de história. Dissertação em Ensino de História - ProfHistória - UFRJ. Rio de Janeiro, 2016.

NAGIB, M. Professor não tem direito a fazer a cabeça do aluno. Consultor Jurídico, 03 de outubro de 2013. Disponível em: <https://www.conjur.com.br/2013-out-03/miguel-nagibprofessor-nao-direito-cabeca-aluno $>$ Acesso em 12 mar. 2020.

NAGIB, M. O Escola Sem Partido e a impostura dos Direitos Humanos do Enem. Gazeta do Povo, 12 de janeiro de 2018. Disponível em: <encurtador.com.br/ast29> Acesso em: 12 mar. 2020.

NAGIB, M. Quem Somos? Escola Sem Partido. 2019. Disponível em: <http://escolasempartido.org/quem-somos/> Acesso em: 12 mar. 2020.

NOVO GAMA-GO. Projeto de Lei $n^{o} 1.516 / 2015$. Pró́be a utilização em escolas públicas municipais de material didático que contenha o que chama de "ideologia de gênero". Novo Gama: 30 de junho de 2015. Disponível em: $<$ https://acessoainformacao.novogama.go.gov.br/legislacao/lei/id=49>. Acesso em: 18 abr. 2020 .

ONU. Declaração Universal Dos Direitos Humanos. Adotada e proclamada pela resolução 217 A (III) da Assembleia Geral das Nações Unidas. ONU, 1948.

PROGRAMA ESCOLA SEM PARTIDO. Deveres do Professor. 2020. Disponível em: $<$ https://www.programaescolasempartido.org/faq > Acesso em: 09 mai. 2020.

PINSKY, J.; PINSKY, C. (Orgs.). História da Cidadania. São Paulo: Contexto, 2013.

PONTES, F. STF suspende lei que institui o programa Escola Livre em Alagoas. Agência Brasil, 22 de março de 2017. Disponível em: $<\underline{\text { https://agenciabrasil.ebc.com.br/politica/noticia/2017-03/stf-suspende-lei-que-instituiu-o- }}$ 
programa-escola-livre-em-alagoas >. Acesso em: 09 abr. 2020.

RIGOLIN, C; HAYASHI, M. Por dentro dos "reservatórios de ideias": uma agenda de pesquisa para os think tanks brasileiros. Liinc em Revista, Rio de Janeiro, v.8, n.1, p. 2033, mar., 2012.

RIO DE JANEIRO. Projeto de Lei $n^{o}$ 2974/2014. Cria, no âmbito do sistema de ensino do Estado do Rio de Janeiro, o Programa Escola Sem partido. Rio de Janeiro: 13 maio 2014. Disponível em: <encurtador.com.br/qPR26>. Acesso em: 18 abr. 2020.

RIO DE JANEIRO. Projeto de Lei $N^{o} 876 / 2014$. Cria, no âmbito do sistema de ensino do município, o "Programa Escola Sem Partido". Rio de Janeiro: 20 de junho de 2014. Disponível em: <encurtador.com.br/afrt1>. Acesso em: 18 abr. 2020.

RODRIGUES, S. Noticioso $x$ noticiário, oficioso $x$ oficial. Blog Sobre Palavras, Veja, 26 de abril de 2012. Disponível em: <https://veja.abril.com.br/blog/sobre-palavras/noticiosox-noticiario-oficioso-X-oficial/>. Acesso em: 16 mai. 2020.

SANTIAGO, A. Escola Sem Partido critica falta de apoio de Bolsonaro e suspende defesa da causa. Gazeta do Povo, 18 de julho de 2019. Disponível em: $<$ https://www.gazetadopovo.com.br/educacao/escola-sem-partido-critica-falta-de-apoiode-bolsonaro-e-suspende-defesa-da-causa/>Acesso em: 12 mar. 2020.

SANTOS, R. Jornalistas e fontes de informação: a sua relação na perspectiva da sociologia do jornalismo, Coimbra: Minerva, 2003.

SAVIANI, D. Pedagogia Histórico-Crítica: primeiras aproximações. 11 ed. Campinas: Autores Associados, 2011.

SECCHI, L. Políticas Públicas: conceitos, esquemas de análise, casos práticos. 2 ed. São Paulo: Cengage Learning, 2013.

SILVA, B. "Eu não trabalho de outra forma, eu penso Enem”: a proposta de Redação do Enem e suas implicações no trabalho com produção de texto em sala de aula. Dissertação (mestrado) - Universidade Estadual da Paraíba, 182 p. João Pessoa, PB: 2017.

TELES, J. Políticas públicas e ensino médio: a perspectiva cidadã da redação do Exame Nacional do Ensino Médio. Encontro Internacional de Formação de Professores e Fórum Permanente de Inovação Educacional, v. 10, n. 1, p. 1-10, 2017.

UNESCO. O perfil dos professores brasileiros: o que fazem, o que pensam, o que almejam. São Paulo: Moderna, 2004.

VALOR ECONÔMICO, STF forma maioria contra lei que veta discussão de gênero nas escolas. Brasília, 25 de abril de 2020. Disponível em: $<$ https://valor.globo.com/politica/noticia/2020/04/25/stf-forma-maioria-contra-lei-queveta-discussao-de-genero-nas-escolas.ghtml. Acesso em: 15 mai. 2020. 
VICENTINI, M. A redação no ENEM e a redação no $3^{\circ}$ ano do ensino médio: efeitos retroativos nas práticas de ensino da escrita. Dissertação (mestrado) - Universidade Estadual de Campinas, Instituto de Estudos da Linguagem. 292 p. Campinas, SP: 2015.

VIANA, C. Oficialmente e oficiosamente. Ciberdúvidas da Língua Portuguesa, 16 de julho de 2017. Disponível em: <encurtador.com.br/biyI5>. Acesso em: 16 mai. 2020.

Recebido em: 05 mai. 2020.

Aceito em: 05 out. 2020. 